\title{
AVALIAÇÃO DO PERFIL LIPÍDICO E HEPÁTICO DE RATOS WISTAR ALIMENTADOS COM DIETA HIPERCALÓRICA E SUPLEMENTADOS COM BIXINA
}

\author{
Patrícia Ferreira da Silva ${ }^{1}$, Leandro Lopes Haidamus ${ }^{2}$, Wanderson Luís de Carvalho ${ }^{3}$ \\ ${ }^{1}$ Instituto Adolfo Lutz - IAL, Pós-graduação em Vigilância Epidemiológica em Saúde Pública. ${ }^{2}$ Docente da Universidade \\ do Oeste Paulista - UNOESTE, Departamento de Ciências Funcionais- Bioquímica, Presidente Prudente, SP. \\ ${ }^{3}$ Universidade Estadual Paulista - UNESP, Assistente de Suporte Acadêmico II, Curso de Zootecnia - Bromatologia, \\ Dracena, SP.
}

\begin{abstract}
RESUMO
A dieta hipercalórica é uma importante indutora de dislipidemias, que pode provocar danos à saúde, especialmente ao fígado. Este trabalho foi desenvolvido com o objetivo de testar a bixina, um carotenoide presente nas sementes do Urucum (Bixa orellana L.), verificando os seus eventuais efeitos sob o metabolismo lipídico e hepático em ratos machos Wistar suplementados com adição de gordura vegetal hidrogenada. Foram utilizados 15 animais, divididos aleatoriamente nos grupos controle (C), hipercalórico (H) e hipercalórico com adição de bixina $(\mathrm{H}+\mathrm{B})$ com cinco animais cada, recebendo alimentação ad libtum pelo período de 25 dias. A dieta com bixina promoveu manutenção do peso, diminuição dos níveis da enzima ALT, diminuição dos níveis de triglicerídeos e aumento de HDL-c. Ainda, a histopatologia hepática evidenciou diminuição da degeneração gordurosa, infiltrado inflamatório e lesão celular.
\end{abstract}

Palavras-chave: bixina, carotenoide, dislipidemias, histopatologia, lipídios, fígado.

\section{EVALUATION OF LIPID AND HEPATIC PROFILE OF WISTAR RATS FED A HYPERCALORIC DIET AND SUPPLEMENTED WITH BIXIN}

\section{ABSTRACT}

The hypercaloric diet is an important inducer of dyslipidemias and, in turn, causes damage to health, especially to the liver. This work was developed with the objective of testing bixin, a carotenoid present in the seeds of annatto (Bixa orellana L.), verifying its side effects on lipid and hepatic metabolism in rats. Fifteen animals were randomly divided into control $(\mathrm{C})$, hypercaloric $(\mathrm{H})$ and hypercaloric groups with bixin $(\mathrm{H}+\mathrm{B})$ with five animals each, receiving feed ad libtum during the period of 25 days. The diet with bixin promoted weight maintenance, decreased ALT levels, decreased triglyceride levels and increased HDL-c. The liver histopathology showed a decrease in fat degeneration, inflammatory infiltrate and cell injury.

Keywords: bixin, carotenoid, dyslipidemias, histopathology, lipids, liver.

\section{INTRODUÇÃo}

As dislipidemias correspondem à disfunção metabólica dos lipídios que causam alterações nas concentrações plasmáticas de lipoproteínas ${ }^{1}$. Podem ser classificadas como primárias quando existe uma causa genética envolvida reconhecida ou não, ou secundárias, ocasionadas por uma condição e/ou doença preexistente ${ }^{2}$. São definidas fenotipicamente pela presença de pelo menos uma das seguintes alterações no perfil lipídico: elevados níveis séricos de Triglicerídeos (TG), Lipoproteína de
Baixa Densidade (LDL-c), e/ou reduzida de Lipoproteína de Alta Densidade (HDL-c), podendo ser encontradas de forma combinada ou isolada ${ }^{3}$. Atualmente sabe-se que mudanças do comportamento alimentar, como a ingestão predominante de alimentos processados, de alta densidade energética, com elevados teores de lipídios e carboidratos, acrescidos de hábitos de vida sedentários, podem culminar com seu desenvolvimento ${ }^{4}$.

O número desses casos é crescente na população, representando um vasto problema de 
saúde pública, já que muitas vezes também estão associados a diversas doenças crônicas, incluindo obesidade, diabetes mellitus tipo 2, resistência insulínica, problemas cardiovasculares (particularmente eventos coronarianos com formação de placas de ateromas), entre outros. Sendo que muitas vezes a evolução é grave, podendo levar ao óbito ${ }^{5}$. Portanto, tornam-se imprescindíveis novas pesquisas e descobertas de compostos para sua prevenção e tratamento ${ }^{6}$.

O fígado é o principal órgão metabolizador, nele os ácidos graxos são esterificados em TG, convertidos em fosfolipídios, ou oxidados em corpos cetônicos ${ }^{7}$ e ocorre, também, a síntese do colesterol. Toda vez que a ingestão de alimentos extrapola a demanda energética, ocorre o acúmulo de reservas (glicogênio e TG) $^{8}$. O consumo de uma dieta rica em calorias resulta num estado pós-prandial de hipertrigliceridemia, hiperglicemia e níveis elevados de ácidos graxos livres na circulação. Desta forma, o fígado é um dos primeiros alvos de uma alimentação hipercalórica, podendo levar a um consequente acúmulo lipídico. Ao acúmulo de TG no citoplasma de células parenquimatosas, designamos degeneração gordurosa, que são alterações celulares geralmente reversíveis quando os estímulos cessam, porém, sob forma grave de deposição, podem ser precursoras da morte celular?.

Outro mecanismo responsável pela lesão celular induzida por excesso de ácidos graxos é o estresse oxidativo, devido ao aumento da produção de espécies reativas de oxigênio, os radicais livres. Estes causam alteração dos lipídios da membrana plasmática e organelas, a peroxidação lipídica, além de alterar os sistemas bioquímicos normais da fisiologia da célula, potencializando o processo de envelhecimento celular $^{10}$. Portanto, o fígado é um excelente indicador de lesão. Logo, os danos hepáticos são de suma importância, exigindo atenção para a manutenção da saúde ${ }^{11}$.

A utilização de plantas para o tratamento e cura de doenças é tão antiga quanto às civilizações humanas ${ }^{12}$. Segundo estudos, alguns corantes naturais têm apresentado propriedades medicinais, tanto para prevenção de processos ateroscleróticos como em outras desordens do metabolismo lipídico ${ }^{1,13-18}$.

A bixina foi isolada pela primeira vez em 1825 por Boussingault e é corante do grupo dos carotenoides presente no revestimento externo da semente da espécie Bixa orellana L., popularmente conhecida no Brasil como urucum $^{19}$. Diversas tem sido as atividades farmacológicas associadas a ela, como potente ação antioxidante, anti-microbiana, hipotensora e antiviral $^{6,20-22}$. Ainda, em uma de suas pesquisas, Lima et al. ${ }^{6}$ avaliaram o metabolismo lipídico de coelhos perante efeitos da norbixina, quercetina e bixina, demonstrando que a última apresentou uma maior redução do colesterol total (CT) e elevação de HDL-c. Moreira et al. ${ }^{23}$, corroborou que este carotenoide também protegeu o fígado de ratos dos efeitos oxidativos provocados pelo tetracloreto de carbono ( $\mathrm{CCl} 4)$, também, dosagens da substância foram testadas em modelos experimentais e não comprovaram sua toxicidade, não sendo observadas alterações no comportamento ou post mortem dos animais ${ }^{24}$.

O Brasil é um produtor em potencial do urucum e este é amplamente utilizado na indústria alimentícia, farmacêutica, têxtil, culinária tradicional, além de sua importância cultural. Seu baixo custo de produção e a possibilidade de cultivo domiciliar permite fácil acesso em todos os níveis sociais. Como o urucum é comumente empregado na alimentação, sua ação protetora é de grande importância ${ }^{25}$, no entanto, seu mecanismo de ação como agente hipolipidêmico e hepatoprotetor in vivo ainda não está completamente determinado. Assim, este trabalho foi desenvolvido com o objetivo de testar uma de suas substâncias de maior abundância, a bixina, verificando os seus eventuais efeitos sob o metabolismo lipídico e hepático em ratos Wistar.

\section{METODOLOGIA}

Neste estudo foram utilizados 15 ratos machos Wistar do Biotério Central da Universidade Estadual Paulista, Campus de Dracena, com pesos entre 150 e $200 \mathrm{~g}$, mantidos em gaiolas específicas, com dimensões de $49 \mathrm{~cm} x$ $34 \mathrm{~cm} \times 16 \mathrm{~cm}$ (comprimento $\times$ largura $\times$ altura) em ambiente com temperatura de $23 \pm 1^{\circ} \mathrm{C}$ com ciclo de luz de $12 \mathrm{~h}$, recebendo ração para roedores e água ad libitum pelo período de 25 dias; sendo divididos aleatoriamente em 3 grupos de 5 animais. Todos os procedimentos foram aprovados pela Comissão de Ética no Uso de Animais (CEUA) da Universidade do Oeste Paulista, protocolo número 2658/2016. 
A dieta foi baseada em protocolo descrito por Pereira ${ }^{26}$ sendo realizadas as seguintes modificações: Grupo Controle (C) foi alimentado apenas com ração padrão comercial, Grupo dieta hipercalórica $(H)$ tratado com adição de $25 \%$ de gordura vegetal hidrogenada à ração padrão comercial e Grupo dieta hipercalórica (H+B) tratado com adição de $25 \%$ de gordura vegetal hidrogenada acrescido de $8 \%$ de bixina (extrato adquirido comercialmente) à ração padrão comercial.

Foi realizado monitoramento dos pesos individuais a cada 3 dias. Após o fim do tratamento de 25 dias, os ratos dos grupos tratados e controle foram anestesiados pela administração via intraperitoneal de Quetamina (90 mg/Kg) e Cloridrato de Xilazina (13 mg/Kg), na dose específica para o peso de roedores de laboratório, conforme a bula do medicamento. $\mathrm{Na}$ sequência foram eutanasiados por decapitação com guilhotina seguindo metodologia estabelecida pela Johns Hopkins University e aprovada pela Fiocruz. Todas as análises foram realizadas nas dependências dos laboratórios de Bioquímica Toxicológica e Morfofisiologia da Faculdade de Ciências Agrárias e Tecnológicas da Universidade Estadual Paulista, Campus de Dracena, sendo realizadas em triplicata.

Amostras de fígado foram coletadas dos animais tratados e controle imediatamente após a eutanásia, sendo fixadas em formaldeído tamponado a $10 \%$, com $\mathrm{pH} 7,4$, posteriormente processadas para estudo histopatológico e coradas pela técnica de hematoxilina e eosina (HE). As amostras de sangue foram coletadas individualmente em tubos tipo Falcon e mantidos à temperatura ambiente por 30 minutos para coagulação. $O$ soro foi separado por centrifugação, com velocidade de $3500 \mathrm{rpm}$ por
15 min. A atividade sérica das enzimas indicadoras de função hepática alanina aminotrasferase (ALT) e aspartato aminotransferase (AST) foi determinada por meio de kit comercial de dosagem enzimática de acordo com as instruções do fabricante (Labstest ${ }^{\circ}$ ). As leituras foram realizadas em um espectrofotômetro Beckman-Coulter modelo DU800 , sob e temperatura $\left(37^{\circ} \mathrm{C}\right)$ controlada ${ }^{27}$. As concentrações de glicose, TG, colesterol total (CT) e HDL-c também foram dosadas no soro por meio de kits comerciais (Labstest ${ }^{\circ}$ ), de acordo com as instruções do fabricante ${ }^{26}$. As leituras foram realizadas utilizando espectrofotômetro Jenway modelo 7305. As concentrações de LDL-c foram estimadas pela equação de Friedewald, onde LDL$\mathrm{c}=\mathrm{CT}-(\mathrm{HDL}-\mathrm{C}+\mathrm{TG} / 5)$.

Os dados experimentais foram apresentados em médias e desvios padrão e submetidos à Análise de Variância (ANOVA), com o pós-teste de Tukey para a comparação de médias entre os grupos, utilizando-se o programa GraphPad Prism, versão 5.0 para Windows, Graphpad Software (San Diego, CA, USA). Os resultados com valor de $\mathrm{p}<0,05$ foram considerados estatisticamente significantes.

\section{RESULTADOS}

Todos os 15 animais selecionados aleatoriamente no início do estudo foram avaliados. Verificou-se diferença estatisticamente significante em relação aos pesos corpóreos depois do 15o dia até o final do tratamento (Figura 1). Neste período, o grupo que recebeu apenas dieta hipercalórica $(\mathrm{H})$ obteve um ganho de peso significativo em relação aos animais dos grupos controle (C) e dieta hipercalórica com adição de bixina $(\mathrm{H}+\mathrm{B})$. 


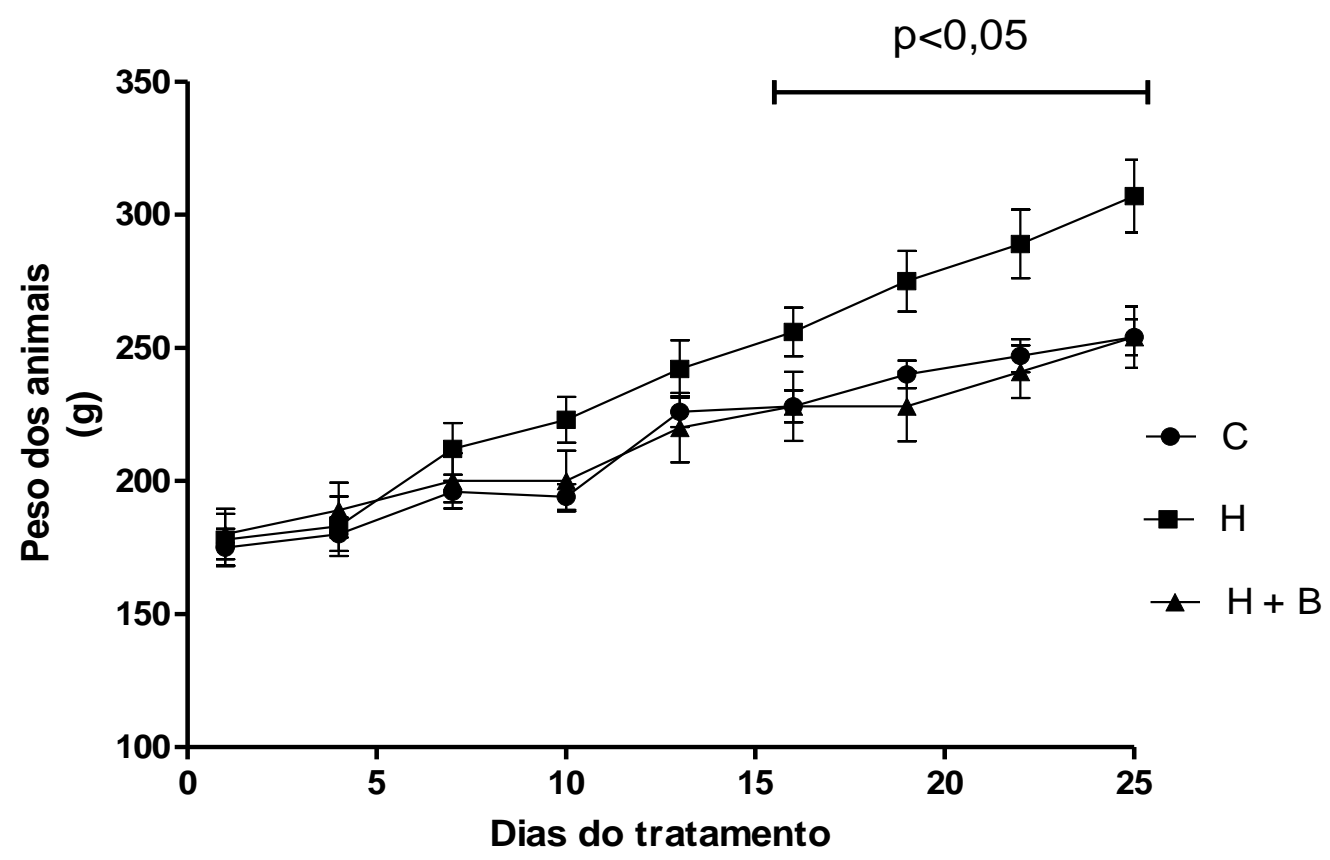

Figura 1. Efeito da bixina sobre ganho de peso corporal induzido por uma dieta hipercalórica em ratos pelo período de 25 dias. Resultados representando a media \pm erro padrão de 5 animais/grupo pesados a cada 3 dias. C: controle; H: dieta hipercalórica; H+B: dieta hipercalórica + bixina. Após 15 dias, C e H+B significativamente diferentes do $\mathrm{H}(\mathrm{p}<0,05)$.

Os animais dos grupos $\mathrm{C}$ e $\mathrm{H}+\mathrm{B}$ não se mostraram significativamente diferentes quanto às concentrações de LDL-c no soro (Figura 2), enquanto que os animais alimentados apenas com dieta hipercalórica $(\mathrm{H})$ apresentaram uma elevação significativa dos níveis dessa fração lipídica quando comparados ao grupo $\mathrm{C}$.

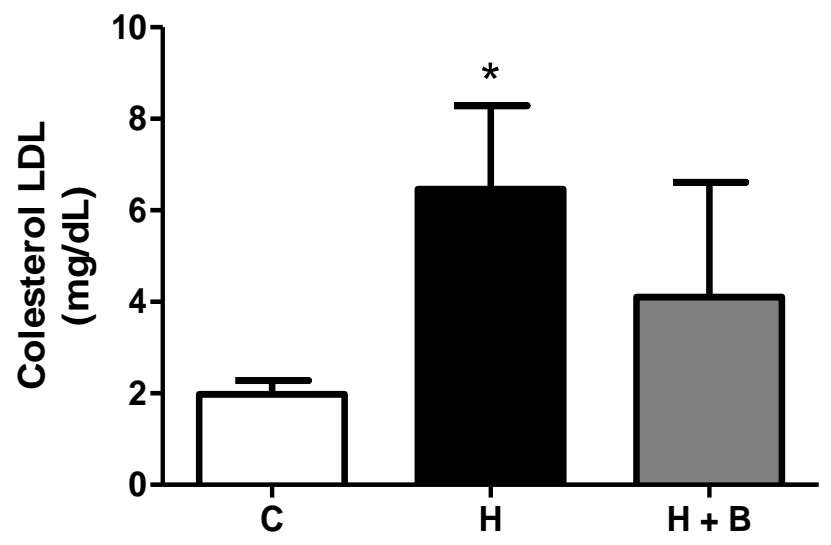

Figura 2. Concentração sérica de colesterol-LDL $(\mathrm{mg} / \mathrm{dL})$ de caga grupo. Resultados representando a media \pm erro padrão de 5 animais/grupo. C: controle; $\mathrm{H}$ : dieta hipercalórica; $\mathrm{H}+\mathrm{B}$ : dieta hipercalórica + bixina. * Diferença significativa em relação ao controle (C) $(p<0,05)$. 
Quanto às concentrações de HDL-c no soro, percebeu-se que, o grupo $\mathrm{H}$ obteve um aumento significativo de suas concentrações quando comparado ao grupo C (Figura 3). Ainda, o $\mathrm{GH}+\mathrm{B}$ demonstrou aumento das concentrações dessa fração lipídica em relação ao grupo $\mathrm{H}$.

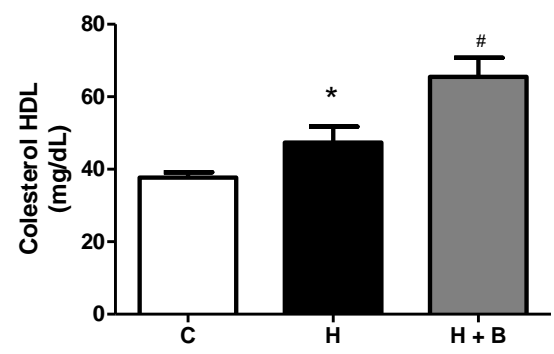

Figura 3. Concentração sérica de colesterol-HDL $(\mathrm{mg} / \mathrm{dL})$ de caga grupo. Resultados representando a media \pm erro padrão de 5 animais/grupo. C: controle; H: dieta hipercalórica; H+B: dieta hipercalórica + bixina. * Diferença significativa em relação ao controle (C) e \#Diferença significativa em relação ao tratado com dieta hipercalórica $(H)(p<0,05)$.

Verificou-se um aumento estatisticamente significativo das concentrações de colesterol total no soro dos grupos tratados $(\mathrm{H}$ e $\mathrm{H}+\mathrm{B})$ em relação ao grupo C. Entretanto, quando comparados, os grupos de animais tratados não demonstraram diferença significativa (Figura 4).

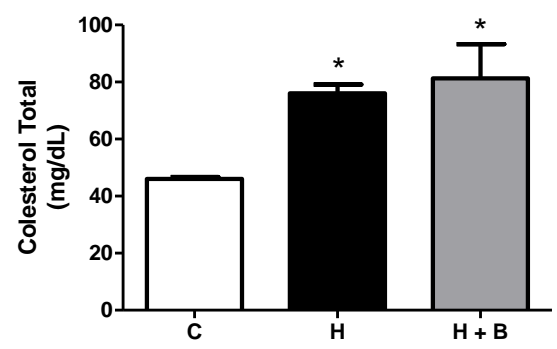

Figura 4. Concentração sérica de colesterol total $(\mathrm{mg} / \mathrm{dL})$ de caga grupo. Resultados representando a media \pm erro padrão de 5 animais/grupo. C: controle; $\mathrm{H}$ : dieta hipercalórica; $\mathrm{H}+\mathrm{B}$ : dieta hipercalórica + bixina. * Diferença significativa em relação ao controle $(C)(p<0,05)$.

Nos níveis de triglicerídeos séricos, identificou-se que o grupo $\mathrm{H}$ obteve um aumento significativo de suas concentrações quando comparado ao grupo C. Ainda, o $\mathrm{GH}+\mathrm{B}$ demonstrou diminuição destas concentrações em relação ao que recebeu apenas alimentação hipercalórica (Figura 5).

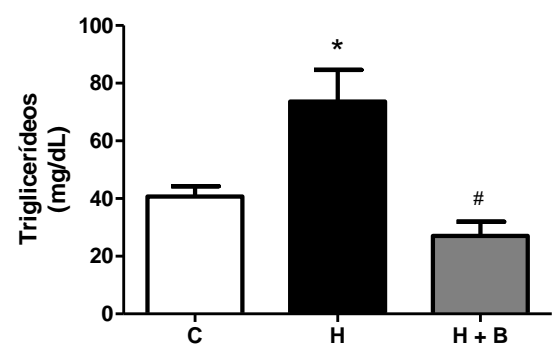

Figura 5. Concentração sérica de triglicerídeos $(\mathrm{mg} / \mathrm{dL})$ de caga grupo. Resultados representando a media \pm erro padrão de 5 animais/grupo. C: controle; $\mathrm{H}$ : dieta hipercalórica; $\mathrm{H}+\mathrm{B}$ : dieta hipercalórica + bixina. *Diferença significativa em relação ao controle (C) e \#Diferença significativa em relação ao tratado com dieta hipercalórica $(H)(p<0,05)$.

Como demonstrado na Figura 6, não houve diferença significativa na concentração sérica de glicose entre o grupo $\mathrm{C}$ e os animais do grupo $\mathrm{H}+\mathrm{B}$. No entanto, observou-se redução 
glicêmica estatisticamente significante deste último grupo em relação aos animais do grupo $\mathrm{H}$.

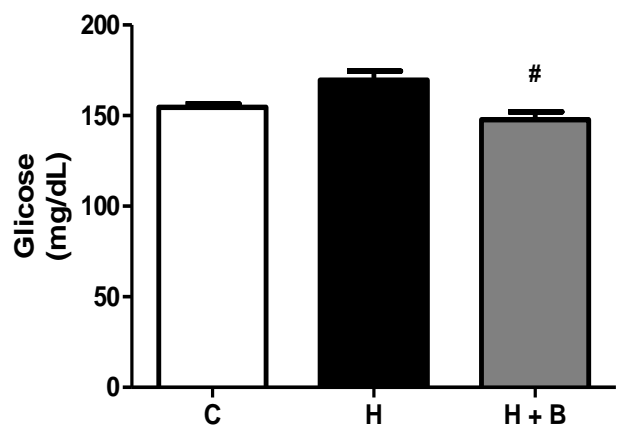

Figura 6. Concentrações sérica de glicose $(\mathrm{mg} / \mathrm{dL})$ de cada grupo. Resultados representando a media \pm erro padrão de 5 animais/grupo. C: controle; $\mathrm{H}$ : dieta hipercalórica; $\mathrm{H}+\mathrm{B}$ : dieta hipercalórica + bixina. \#Diferença significativa em relação ao tratado com dieta hipercalórica $(H)(p<0,05)$.

Houve um aumento significativo da atividade sérica de AST dos grupos tratados $(\mathrm{H}$ e $\mathrm{H}+\mathrm{B}$ ) em comparação com ao grupo C (Figura 7).
Porém, os grupos tratados não obtiveram resultados estatisticamente significativo quando comparados.

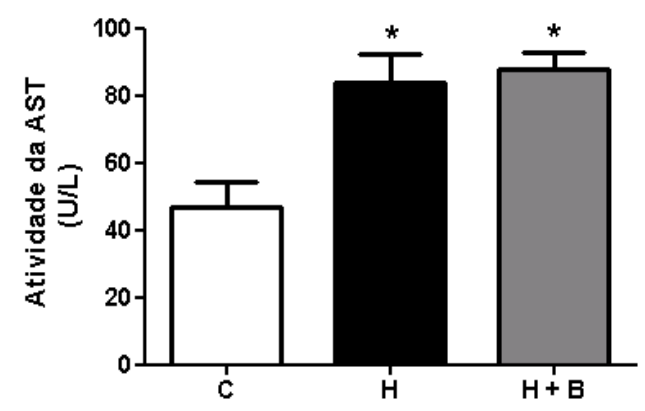

Figura 7. Valores da atividade de aspartato aminotransferase (AST) de cada grupo. Resultados representando a media \pm erro padrão de 5 animais/grupo. $\mathrm{C}$ : controle; $\mathrm{H}$ : dieta hipercalórica; $\mathrm{H}+\mathrm{B}$ : dieta hipercalórica + bixina. *Diferença significativa em relação ao controle $(C)(p<0,05)$.

Observou-se elevação da atividade de ALT no grupo $\mathrm{H}$ em relação ao grupo C. Ainda, quando comparados, os grupos tratados demonstraram-se diferentes, já que houve uma dimuição significativa do grupo $\mathrm{H}+\mathrm{B}$ em relação ao grupo H (Figura 8).

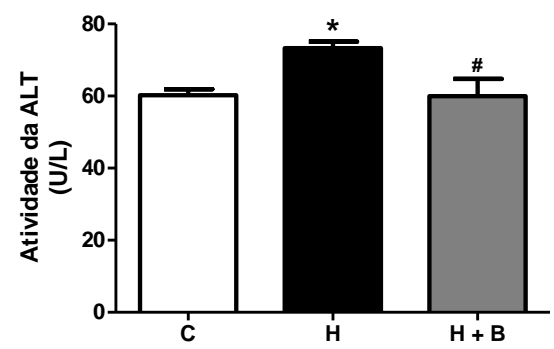

Figura 8. Atividade sérica de alanina aminotransferase (ALT) de cada grupo. Resultados representando a media \pm erro padrão de 5 animais/grupo. C: controle; $\mathrm{H}$ : dieta hipercalórica; $\mathrm{H}+\mathrm{B}$ : dieta hipercalórica + bixina. *Diferença significativa em relação ao controle (C) e \#Diferença significativa em relação ao tratado com dieta hipercalórica $(H)(p<0,05)$.

A análise histopatológica do fígado dos animais do grupo $C$ não demonstrou alteração dos hepatócitos, incluindo processo inflamatório. No grupo $\mathrm{H}$ ocorreu degeneração gordurosa moderada à acentuada com presença de infiltrado inflamatório mononuclear (linfócitos e plasmócitos) e polimorfonuclear (neutrófilos mais evidentes) moderado nos sinusoides, espaço porta e veia centrolobular. Os animais do grupo $\mathrm{H}+\mathrm{B}$ apresentaram degeneração gordurosa 
discreta e aleatória com infiltrado inflamatório mononuclear (linfócitos e plasmócitos principalmente) e polimorfonuclear (neutrófilos raros) discreto nos sinusoides.

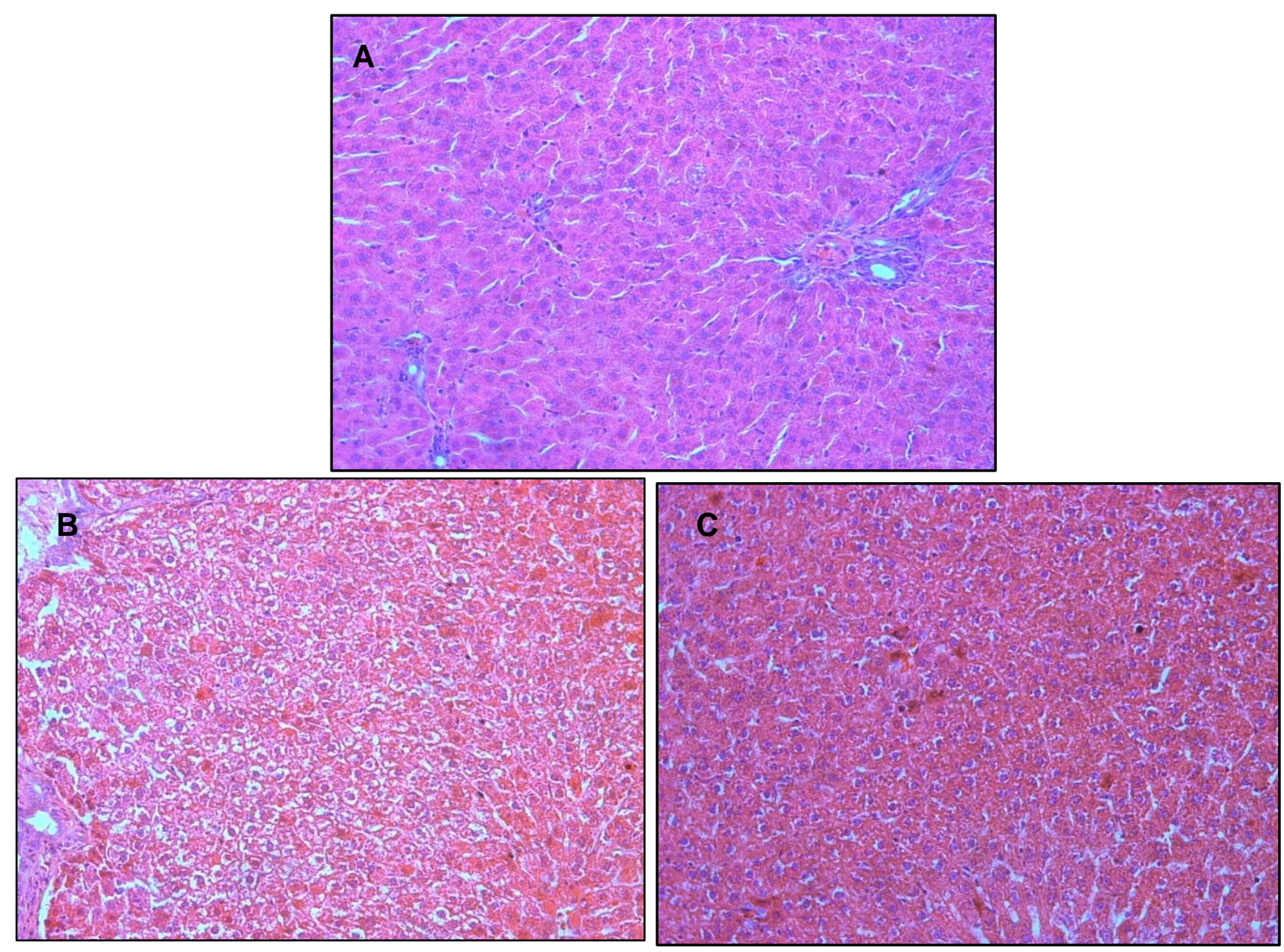

Figura 9. Histologia hepática representativa dos animais dos grupos. A: controle (C); B: dieta hipercalórica (H); C: dieta hipercalórica + bixina (H+B). Aumento de 200X.

\section{DISCUSSÃO}

Muitos achados científicos incluem a ingestão de uma dieta hipercalórica e/ou hiperlipídica como fator de risco à obesidade e outras modificações no metabolismo, que podem levar à alteração da homeostasia corpórea ${ }^{28}$. Alimentos com alto teor de lipídios ou carboidratos são, então, frequentemente utilizados em modelos animais para induzir distúrbios metabólicos que são comuns em seres humanos $^{29}$. Ao passo que estudos epidemiológicos têm demonstrado que a ingestão de alimentos como frutas e vegetais, correlacionam-se inversamente à prevalência dessas doenças, principalmente às neoplasias, hipertensão, problemas cardiovasculares, inclusive as dislipidemias. Isto também é válido para os carotenoides, já que a maioria deles provém desses alimentos ${ }^{30}$.

A bixina é obtida por meio da espécie Bixa orellana $\mathrm{L}$, conhecida popularmente como urucum, e pertence ao grupo dos carotenoides. Vários são os estudos associados às suas possíveis características medicinais, dentre elas, algumas propriedades hipolipidêmicas e hepatoprotetoras.

Neste modelo experimental, a quantidade de ração oferecida para os três grupos foi igual, sendo a ingesta individual ad libtum. Assim como Macedo ${ }^{31}$ observou-se um aumento significativo do peso dos animais tratados com dieta hipercalórica $(\mathrm{H})$ em relação ao controle (C). Provavelmente, isto atribuiu-se à alimentação altamente energética enriquecida com $25 \%$ de gordura vegetal hidrogenada. 0 
autor citado relata que, uma dieta hipercalórica provoca o aumento do peso corporal e do tecido adiposo visceral independente do gênero e idade dos animais. Ainda, os resultados levaram a crer que a suplementação com a bixina não alterou a palatabilidade e a quantidade de ração ingerida, influenciando inclusive no peso dos animais, sendo perceptível pela tendência de proximidade do grupo que recebeu dieta hipercalórica com bixina $(\mathrm{H}+\mathrm{B})$ e o grupo $\mathrm{C}$.

As concentrações triglicerídeas e/ou de colesterol estão intimamente ligadas às hiperlipidemias $^{26}$. Logo, o processo de caracterização do perfil lipídico neste estudo foi realizado por meio de análises bioquímicas no soro dos roedores.

Os dados revelaram que o grupo $\mathrm{H}$ obteve uma concentração média de LDL-c superior ao grupo $\mathrm{H}+\mathrm{B}$, apesar de uma ampla variância. Provavelmente, os níveis de concentração desta lipoproteína seriam menores nos animais do grupo $\mathrm{H}+\mathrm{B}$ caso o período de tratamento fosse estendido e/ou a porcentagem da substância na dieta estivesse maior.

Atualmente sabe-se que HDL-c não se limita apenas em realizar o transporte reverso do colesterol, mas também possui efeitos antiinflamatórios, antioxidantes e vasodilatadores ${ }^{32}$. Lima et al. ${ }^{6}$ num modelo experimental com coelhos, demonstrou que a bixina mantém os níveis de HDL-c mais elevados, o que condiz aos resultados obtidos, pois o grupo que a consumiu $(\mathrm{H}+\mathrm{B})$ atingiu um aumento significativo dessa fração lipídica quando comparado ao que ingeriu apenas a dieta hipercalórica (H). Entretanto, contrariamente aos autores, que verificaram o efeito deste carotenoide sobre a redução do $\mathrm{CT}$, o presente estudo evidenciou uma elevação significativa deste parâmetro em ambos os grupos tratados ( $\mathrm{H}$ e $\mathrm{H}+\mathrm{B}$ ) em relação ao grupo $\mathrm{C}$, possivelmente pela administração da alimentação rica em lipídeos; diferença da composição dietética dos autores citados, que utilizaram: ração + colesterol + ácido cólico + bixina; além das concentrações elevadas de HDLc do grupo H+B. Ainda, as gorduras hidrogenadas são ricas em ácidos graxos insaturados, que aumentam o colesterol total e LDL-c. Logo, os resultados obtidos para colesterol total não foram considerados significantes.

Diferentemente de Pereira ${ }^{26}$, que não observou diferença significativa nos níveis de triglicerídeos em seu estudo sobre a ação antioxidante da bixina mediante os processos de lipoperoxidação, a adição deste carotenoide na alimentação ad libtum revelou uma tendência de valores normais, próximos ao encontrado no grupo C, sendo supostamente eficaz na diminuição das concentrações destes lípides. Este mecanismo foi elucidado por Lima et al. ${ }^{2}$ que evidenciou a bixina com potente ação ativadora da lipase lipoproteica in vitro, e com isso, contribuiria para a remoção dos triglicerídeos na circulação sanguínea ${ }^{11}$.

A literatura tem relatado que a norbixina, um dos pigmentos também encontrados nas sementes de ucurum, tem apresentado propriedades hiperglicemiantes em ratos e hipoglicêmicas em camundongos ${ }^{33}$. Contudo, escassos são os trabalhos referentes a investigação dos benefícios da bixina sobre o metabolismo de carboidratos. Neste estudo, a substância demonstrou um potencial hipoglicemiante, pois $\mathrm{GH}+\mathrm{B}$ obteve concentração glicêmica inferior em relação ao grupo $\mathrm{H}$.

Ao projetarmos estes resultados para a realidade do cotidiano humano, presumivelmente, este extrato na dieta poderia atuar como interferente no perfil lipídico, e este por sua vez nas dislipidemias. Apesar de não ter surtido efeito sobre as concentrações de colesterol total, demonstrou-se eficaz quanto à manutenção do peso, elevações de HDL-c e diminuição de TG. Além disto, estudos futuros poderão compreender melhor o efeito desta substância que demonstra ser promissora também na redução de LDL-c.

O fígado produz diversas transaminases, dentre elas são de maior importância clínica ALT e AST. A primeira é considerada mais específica para agressão hepática e tem origem quase exclusivamente citoplasmática. A segunda localiza-se $60 \%$ na mitocôndria e $40 \%$ no citoplasma dos hepatócitos, porém, também apresenta concentrações elevadas em músculo cardíaco, esquelético, e em menor proporção em rins, pâncreas e hemácias ${ }^{34}$. A relação entre as duas fornece a perspectiva clínica sobre várias doenças hepáticas ${ }^{35}$.

Os dados obtidos revelaram aumentos significativos da atividade sérica de AST nos grupos tratados, porém, sem diferença entre ambos, indicando lesão inespecífica, especialmente quando comparados com o grupo C. Neste sentido pode-se utilizar este resultado como possível parâmetro para lesão hepática ou 
de outros órgãos onde ela se encontra, provocada pela dieta lipídica ${ }^{27}$.

A ALT, de maior especificidade, evidenciou redução de sua atividade no grupo $H+B$ quando comparada ao grupo $H$, se equiparando inclusive ao grupo $\mathrm{C}$, demonstrando o possível efeito hepatoprotetor da bixina. No entanto, as dosagens da atividade das transaminases não podem serem utilizadas para determinar o grau da lesão ou oferecer um prognóstico futuro, porque não medem a extensão do dano no fígado ${ }^{34,35}$. Assim, para avaliação dos níveis de acometimento do órgão foram realizadas análises histopatológicas.

As lesões hepáticas apresentam padrões de respostas características ao agente causador do dano. Nas dislipidemias é comum encontrar esteatose macro e microvesicular, processos inflamatórios nas zonas portal e parenquimatosa e, nos casos graves, podendo culminar em necrose e apoptose ${ }^{8}$. Os animais do grupo $C$ possuem resultado da análise histopatológica normais, concordando com os valores encontrados tanto nas enzimas ALT e AST, com o colesterol total, suas frações, e TG. Os resultados das análises dos animais do grupo $\mathrm{H}$ demonstraram que a dieta hiperlipídica causou danos ao fígado, evidenciada pela degeneração gordurosa dos hepatócitos (macro e microvesicular), especialmente com infiltrado inflamatório encontrado nos espaços porta e periportal. Estes resultados são semelhantes aos encontrados por $\mathrm{Borba}^{36}$, que demonstrou o efeito da dieta hipercalórica em ratos Wistar, com achados de esteatose e alteração em parâmetros anatômicos.

No caso do grupo tratado $\mathrm{H}+\mathrm{B}$ pode-se associar ao efeito protetor da bixina ao diminuir o processo inflamatório e o grau de degeneração celular, assim como descrito por Moreira et al. ${ }^{23}$. O mecanismo de proteção talvez se dê pelo efeito antioxidante da substância, demonstrado por Pereira $^{26}$ que sugere diminuição da peroxidação da membrana plasmática dos hepatócitos e consequente dano celular com extravasamento do conteúdo citoplasmático, corroborando os resultados das dosagens séricas de ALT e AST ${ }^{24}$.

\section{CONCLUSÃO}

Desta forma, conclui-se que o extrato de bixina exerceu efeito positivo nos exames laboratoriais frente à dislipidemia induzida por acréscimo de gordura na dieta, evidenciados pelos resultados nas dosagens de ALT, triglicerídeos, HDL-c, glicose e evolução da massa corpórea no período de tratamento.

\section{CONFLITOS DE INTERESSE}

Os autores declaram não haver qualquer potencial conflito de interesses que possa interferir na imparcialidade deste trabalho científico.

\section{REFERÊNCIAS}

1. Xavier HT, Izar MC, Faria NJR, Assad MH, Rocha VZ, Sposito AC, et al. V Diretriz Brasileira de Dislipidemias e Prevenção da Aterosclerose. Arq Bras Cardiol. 2016;101(4):1-20. DOI: http://dx.doi.org/10.5935/abc.20135010

2. Lima LRP, Oliveira TT, Nagem TJ, Pinto AS, Stringhetta PC, Tinoco ALA, Silva JF. Efeito de flavonóides (luteolina e apigenina) e corantes naturais (norbixina e bixina) do urucum sobre a atividade da lipase. Rev Esc Farm Odontol Alfenas. 1999;21:29-36. DOI: http://dx.doi.org/10.1590/S1413-

\section{0}

3. Garcez MR, Pereira JL, Fontanelli MM, Marchioni DML, Fisberg RM. Prevalência de dislipidemia segundo estado nutricional em amostra representativa de São Paulo. Arq Bras Cardiol. 2014;103(6):476-84. DOI: http://dx.doi.org/10.5935/abc.20140156

4 Snyder EE, Walts B, Pérusse L, Chagnon YC, Weisnagel SJ, Rankinen T, Bouchard, C. The human obesity gene map: the 2003 update. Obes Res. 2004;12:369-439.

DOI:

http://dx.doi.org/10.1038/oby.2004.47

5. Xavier HT, Izar MC, Faria NJR, Assad MH, Rocha VZ, Sposito AC et al. IV Diretriz brasileira sobre dislipidemias e prevenção da aterosclerose. Arq Bras Cardiol. 2007;88(1):2-19. DOI: http://dx.doi.org/10.1590/S0066782X2007000700002

6. Lima LRP, Oliveira TT, Nagem TJ, Pinto AS, Stringhetta PC, Tinoco ALA, Silva JF. Bixina, norbixina e quercetina e seus efeitos no metabolismo lipídico de coelhos. Braz J Vet Res Anim Sci. 2001;38(4):196-200. DOI: http://dx.doi.org/10.1590/S1413$\underline{95962001000400010}$ 
7. Lee RJ. Fatty change and steatohepatitis. Diagnostic Liver Pathology: Sant Louis: MosbyYear Book; 1994.

8. Malheiros SVP. Integração metabólica nos períodos pós-prandial e de jejum - um resumo. Rev Bras Ens Bioq Biol Mol. 2006;4(1):16-22. DOI: https://doi.org/10.16923/reb.v4i1.20

9. Robbins S, Kumar V, Abbas AK. Patologia: bases patológicas das doenças. 7.ed. Rio de Janeiro: Elsevier; 2005. P.482-7.

10. Newmeyer DD, Fergunson MS. Mitochondria releasing power for life and unleashing the machineries of death. Cell. 2003;112(4):481-90. DOI: http://dx.doi.org/10.1016/S0092-

8674(03)00116-8

11. Schiavo M, Lunardelli A, Oliveira JR. Influência da dieta na concentração sérica de triglicerídeos. J Bras Patol Med Lab. 2003;39(4):283-8. DOI: http://dx.doi.org/10.1590/S1676-

$\underline{24442003000400004}$

12. Moreira VS. Atividade antioxidante e caracterização físico-química de variedades de urucueiros in natura e encapsulado. [Dissertação]. Bahia: Universidade Estadual do Sudoeste da Bahia, 2013.

13. Goker $H$, Tuncbilek $M$, Leoncini G, Buzzi E, Mazzei $M$, Rolland $Y$ et al. Synthesis and inhibitory activities on platelet aggregation of some flavonoid analogues. Drug Res. 1995;45(7):372-6.

14. Lemos VS, Freitas MR, Muller B, Lino YD, Queiroga CEG, Cortes SF. Dioclein, a new nitric oxide and endothelium dependent vasodilator flavonoid. Eur J Pharm Sci. 1999;386(8):41-6. DOI: http://doi.org/10.1016/S0014-2999(99)00747-5

15. Silva CR, Antunes LMG, Bianchini MLP. Antioxidant action of bixin against cisplatininduced chromosome aberrations and lipid peroxidation in rats. Pharmacol Res. 2001;43(6):561-7.

DOI:

https://doi.org/10.1006/phrs.2001.0822

16. Natan I, Chahuri G. Estrogens and atherosclerosis. Annu Rev Pharmacol Toxicol, 1997;37(4):477-552. http://doi.org/10.1146/annurev.pharmtox.37.1.4 $\underline{77}$

17. Pereira WL, Oliveira TT, Nagem TJ, Pinto AS, Stringheta PC, Oliveira MGA. Redução nos níveis de lipídeos utilizando o flavonóide biochanina A e os corantes monascus e clorofila. Rev Bras Corantes Nat. 1999;3(3):59-65.

18. Samman S, Wall PML, Cook NC. Flavonoids and coronary heart disease: dietary perspectives. In: JA Manthey, BS Buslig (Eds.). Flavonoids in the living system. New York: Plenum Press; 1999. P.469-81.

19. Taham T, Cabral FA, Barrozo, Marcos AS. Extração da bixina do urucum utilizando diferentes tecnologias. Blucher Chem Engineer Proc. 2015;1(2):16232-9. DOI: http://dx.doi.org/10.5151/chemeng-cobeq20141930-16817-141974

20. Fleisher TC, Ameade EP, Mensah ML, Sawer IK. Antimicrobial activity of the leaves and seeds of Bixa orellana. Fitoterapia. 2003;(74):136-8. DOI: http://dx.doi.org/10.1002/ptr.5088

21. Rodrigues LA, Fracasso JF, Yashuda Y. The hipotensive action of the extracts from seeds of Bixa orellana L. Rev Bras Ciênc Farm. 1998;10:414.

22. Cácerez $A$, Menéndez $H$, Méndez $E$, Cohobón E, Samayoa BE, Jauregui E, et al. Antigonorrhoeal activityof plants used in Guatemala for the treatment of sexually transmitted diseases. J Ethnopharmacol. 1995;48:85-8. DOI: https://doi.org/10.1016/0378-8741(95)01288-0

23. Moreira, PR. Atividade antioxidante da bixina sobre os danos causados pelo tetracloreto de carbono no fígado de ratos. [Dissertação]. Araçatuba: Faculdade de Medicina Veterinária de Araçatuba-UNESP, 2012.

24. Bautista ARPL, Miranda MS, Batista MS, Moreira ELT, Silva IM, Gomes ICS. Avaliação da toxicidade oral subcrônica da bixina para ratos. Rev Bras Ciênc Farm. 2004;40(2):229-33. DOI: http://dx.doi.org/10.1590/S1516$\underline{93322004000200012}$ 
25. Winita $H$, Frederick JS. Hepatobiliary function. Med Physiol. 2003;45(1):975-1002.

26. Pereira RC. Atividade hipolipidêmica e protetora da bixina no fígado de ratos tratados com dieta hipercalórica. [Dissertação]. Araçatuba: Faculdade de Medicina Veterinária de Araçatuba - UNESP, 2013.

27. Carvalho WL, Maioli MA, Mendes LCN, Rozza $\mathrm{DB}$, Mingatto FE. Mecanismos da intoxicação do fígado de rato causada pelo gossipol. Pesq Vet Bras. 2013;33(3):339-44. DOI: http://dx.doi.org/10.1590/S0100736X2013000300011

28. Zhang L, Robert VC, John SB. Carotenoids enhance gap junctional communication and inhibit lipid peroxidation in $\mathrm{C} 3 \mathrm{H} / 10 \mathrm{~T} 1 / 2$ cell: relationship to their cancer chemopreventive action. Carcinogenesis. 1991;12(11):2109-14. https://doi.org/10.1093/carcin/12.11.2109

29. Júnior SAO, Okoshi K, Leopoldo APL, Leopoldo AS, Campos DHS, Martinez PF et al. Perfil nutricional e Cardiovascular de Ratos normotensos e Hipertensos sob dieta Hiperlipídica. Arq Bras Cardiol. 2009;93(5):52633. DOI: http://dx.doi.org/10.1590/S0066782X2009001100014

30. Consumo de carotenoides e polifenóis em indivíduos com risco cardiometabólico. Nutr Clín Diet Hosp. 2016;36(3):138-45. DOI: http://dx.doi.org/10.12873/363paulaalmeida

31. Macedo IC. Estresse crônico associado à dieta hipercalórica em ratos Wistar: parâmetros ponderais e bioquímicos. [Dissertação]. Porto Alegre: Universidade Federal do Rio Grande do Sul, 2010.

32. Hayden MR, Tyagi SC. Isolated low high density lipoprotein-cholesterol (HDL-C): implications of global risk reduction. Case report and systemic scientific review. Cardiovasc Diabetol. 2005;4(1):1. DOI: https://doi.org/10.1186/1475-2840-4-1

33. Fernandes ACS, Almeida CA, Albano F, Laranja Gustavo AT, Felzenszwalb I, Lage CLS et al. Norbixin ingestion did not induce any detectable DNA breakage in liver and kidney but caused a considerable impairment in plasma glucose levels of rats and mice. J Nutr Biochem. 2002;13(7):411-
20. DOI: https://doi.org/10.1016/S09552863(02)00177-8

34. Strauss E. Hepatite C. Rev Soc Bras Med Trop. 2001;34(1):69-82.

DOI:

http://dx.doi.org/10.1590/S0037-

86822001000100011

35. Branco ACSC, Diniz MFFM, Almeida RN, Santos HB, Oliveira KM, Ramalho JA et al. Parâmetros bioquímicos e hematológicos de ratos wistar e camundongos swiss do biotério professor Thomas George. Rev Bras Ciênc Saúde. 2011;15(2):209-14. DOI: http://dx.doi.org/10.4034/RBCS.2011.15.02.11

36. Borba AJ. Efeito da dieta hiperlipídicoprotéica no metabolismo de ratos wistar adultos. [Dissertação]. Uberaba: Universidade Federal do Triângulo Mineiro, 2008.

Recebido para publicação em 13/11/2017

Revisado em 03/04/2018

Aceito em 03/07/2018 